Pure Appl. Chem., Vol. 72, Nos. 1-2, pp. 327-331, 2000.

(C) 2000 IUPAC

\title{
Effect of nanostructured supports on catalytic methane decomposition*
}

\author{
L. Ji, S. Tang, P. Chen, H. C. Zeng ${ }^{1}$, J. Lin', and K. L. Tan \\ Surface Science Laboratory, Department of Physics, 'Department of Chemical \\ Engineering; National University of Singapore, Singapore 119260
}

\begin{abstract}
Carbon deposition from catalytic methane decomposition has drawn increasing interest recently. Previously, we have found the carbon formation depends on the crystalline structure of the support, following the trend of $\mathrm{Ni} / \mathrm{CeO}_{2}>\mathrm{Ni} / \mathrm{CaO}>\mathrm{Ni} / \mathrm{MgO}$, because $\mathrm{Ni}$ supported on $\mathrm{MgO}$ is uniformly dispersed and can stabilize high-x $\mathrm{CH}_{\mathrm{x}}$ intermediates. We have also found that the addition of $\mathrm{Pt}$ can inhibit the carbon deposition on $\mathrm{Co} / \mathrm{Al}_{2} \mathrm{O}_{3}$ because the alloying between $\mathrm{Pt}$ and Co results in the better dispersion of Co on the support. Furthermore, it was revealed that by judging the Ni/Mg molar ratio from 1 to 0.25 we could reduce the diameter of deposited carbon nanotubes from 20 to $12 \mathrm{~nm}$, with substantially smaller production rate. All of these previous studies indicated that better dispersion of the supported metal would benefit the decreasing of carbon deposition. Here we present our recent investigation of the effect of support particle size on the carbon deposition. Three different types of $10 \mathrm{wt} \% \mathrm{Co} / \mathrm{Al}_{2} \mathrm{O}_{3}$ catalysts were prepared: Co on commercial $\mathrm{Al}_{2} \mathrm{O}_{3}$ (Cat 1), Co on sol-gel-processed $\mathrm{Al}_{2} \mathrm{O}_{3}$ (Cat 2), and sol-gel-made homogeneous Co-in- $\mathrm{Al}_{2} \mathrm{O}_{3}$ (Cat 3). TEM showed that the diameter of the $\mathrm{Co}_{3} \mathrm{O}_{4}$ particles in sol-gel $\mathrm{Al}_{2} \mathrm{O}_{3}$ is only around $6 \mathrm{~nm}$, while it is $20-40 \mathrm{~nm}$ in the commercial catalyst. By using XRD and FTIR, Co was identified as crystalline $\mathrm{Co}_{3} \mathrm{O}_{4}$ in the as-prepared Cat 1 sample, $\mathrm{CoAl}_{2} \mathrm{O}_{4}$ in Cat 2, and amorphous $\mathrm{Al}_{2} \mathrm{O}_{3}$ in Cat 3, indicating the best dispersion in Cat 3. Methane $\mathrm{CO}_{2}$ reforming was studied on the three catalysts. Longer lifetime was measured for Cat 3 as compared to those on Cat 1 and Cat 2 ( $>20 \mathrm{~h}$ vs. $1 \mathrm{~h}$ ). The support size effect is discussed.
\end{abstract}

Carbon deposition from catalytic methane decomposition has drawn increasing interest recently. The deposited carbon may appear as coke, resulting in the catalyst deactivation or the plugging of reactors [1]. Alternatively, it may form surface carbides that can be converted to more valuable hydrocarbons by the subsequent low-temperature hydrogenation [2,3]. Moreover, we have very recently found that the deposited carbon can occur in the form of nanotubes with open-edged structure and can possess high capacity of hydrogen uptake after alkali-doping [4].

In a comparative study [5], carbon deposition from methane decomposition was found to depend on the crystalline structure of the support. $\mathrm{Ni}$ supported on $\mathrm{MgO}$ has shown an excellent resistance, much better than that on $\mathrm{CeO}_{2}$ and $\mathrm{CaO}$, to the coke formation during the partial oxidation of methane to syngas at atmospheric pressure, $750{ }^{\circ} \mathrm{C}$ and high methane/oxygen ratios. This is because $\mathrm{NiO}$ and $\mathrm{MgO}$ can form an ideal solid solution. As a result, $\mathrm{Ni}$ is uniformly dispersed in the $\mathrm{MgO}$ matrix after its reduction. The highly distributed $\mathrm{Ni}$ can favorably stabilize high-x $\mathrm{CH}_{\mathrm{x}}$ intermediates and therefore retard the deposition of carbon.

*Pure Appl. Chem. 72, 1-331 (2000). An issue of reviews and research papers based on lectures presented at the $1^{\text {st }}$ IUPAC Workshop on Advanced Materials (WAM1), Hong Kong, July 1999, on the theme of nanostructured systems. $\dagger$ Corresponding author: E-mail: phylinjy@nus.edu.sg; Fax: 00657776126; Tel: 00658742616 

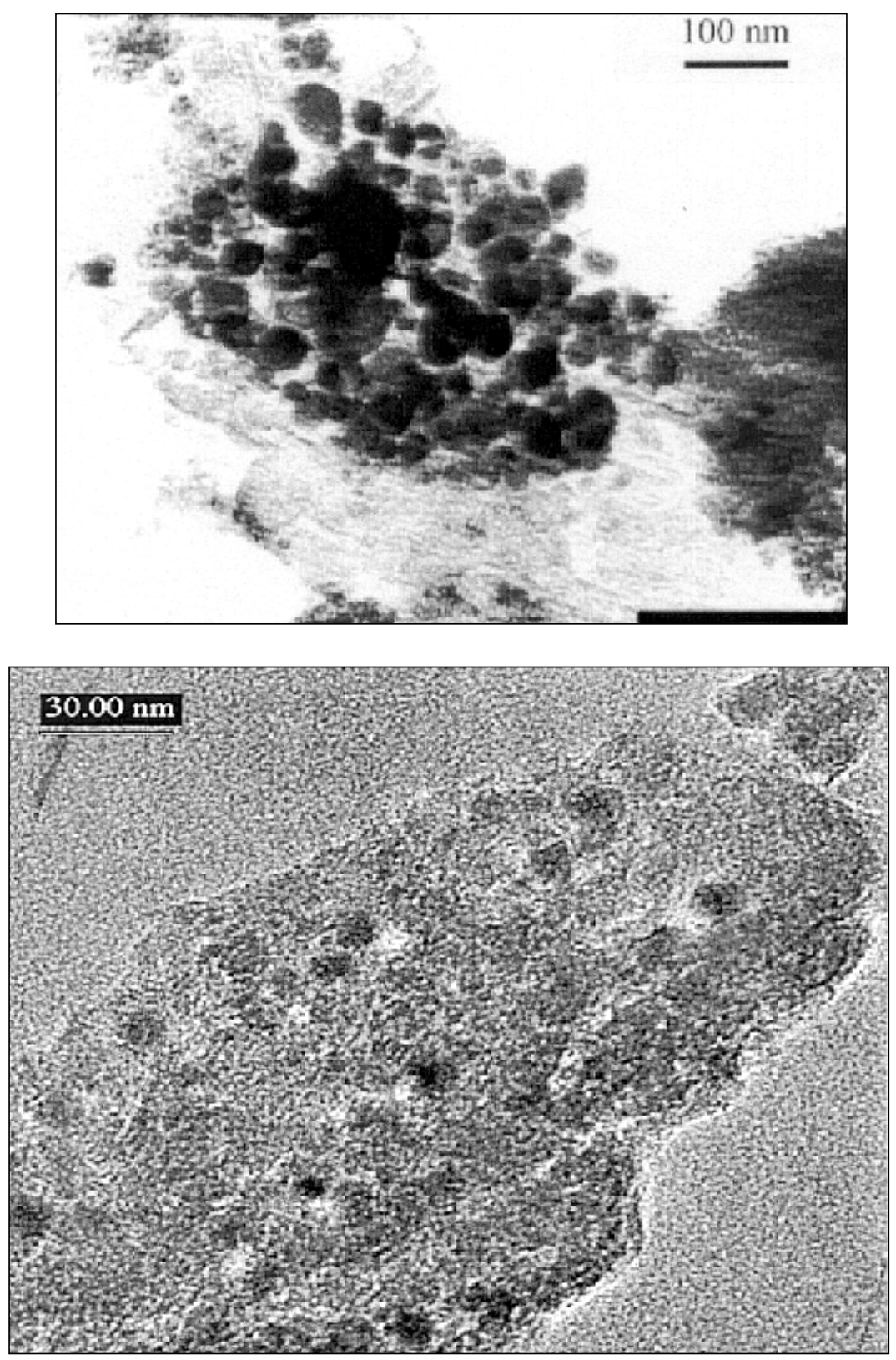

Fig. 1 TEM image of (a) $10 \mathrm{wt} \%$ Co supported on commercial $\gamma-\mathrm{Al}_{2} \mathrm{O}_{3}$; (b) sol-gel-processed $10 \mathrm{wt} \%$ Co-in$\mathrm{Al}_{2} \mathrm{O}_{3}$.

In the experiments of preparing carbon nanotubes from the methane decomposition over $\mathrm{Ni} /$ $\mathrm{MgO}$ catalysts, we have observed that by judging the $\mathrm{Ni} / \mathrm{Mg}$ molar ratio from 1 to 0.25 , the Ni particles, and hence the deposited carbon nanotubes, reduce their diameter from 20 to $12 \mathrm{~nm}$. The carbon deposition rate is also substantially decreased [6]. 


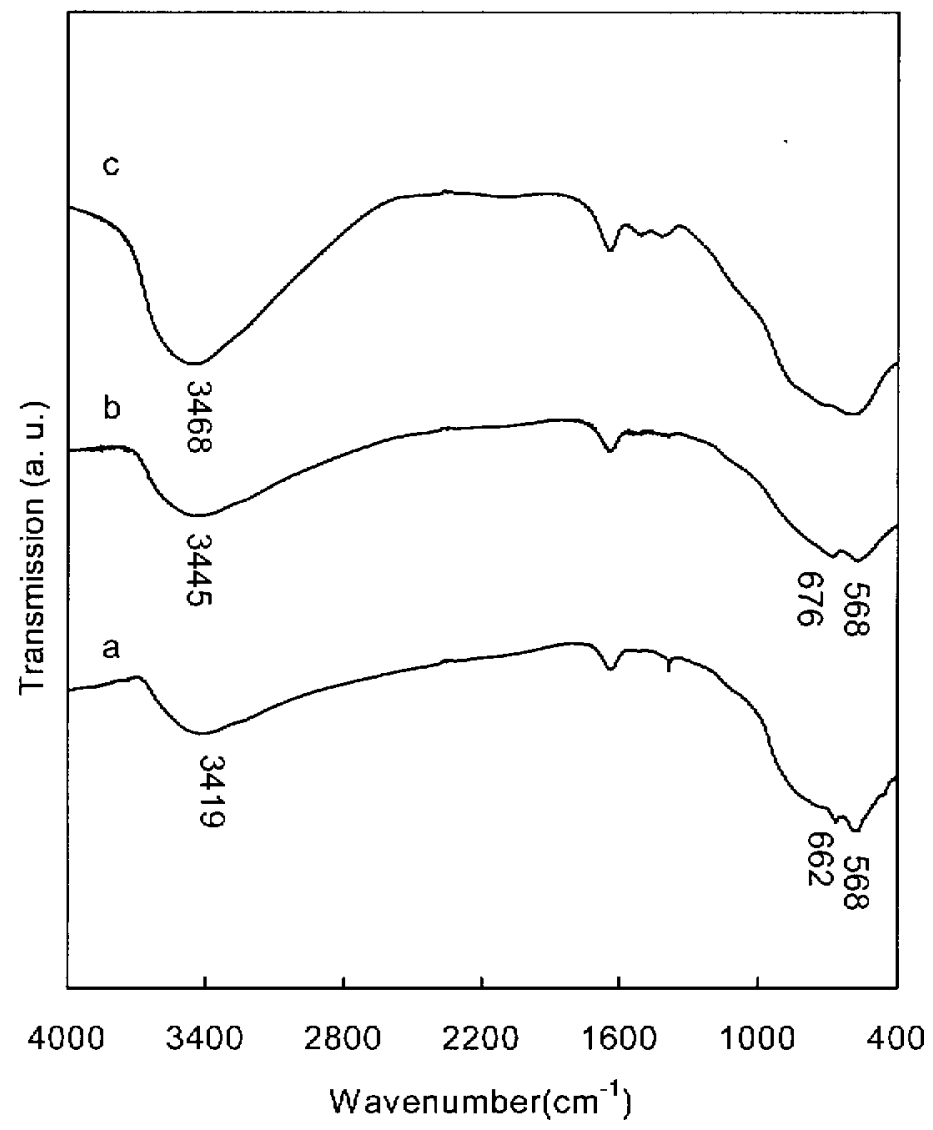

Fig. 2 FTIR spectra for the as-prepared catalysts: (a) Co/commercial $\gamma-\mathrm{Al}_{2} \mathrm{O}_{3}$; (b) $\mathrm{Co} / \mathrm{sol}$-gel $\mathrm{Al}_{2} \mathrm{O}_{3}$, (c) sol-gelprocessed homogeneous Co-in- $\mathrm{Al}_{2} \mathrm{O}_{3}$.

We have also found that alloying can greatly enhance the distribution of Co metal in the $\mathrm{Al}_{2} \mathrm{O}_{3}$ supported catalysts, hence increasing its resistance to the carbon deposition during partial oxidation of methane to syngas. By using $\mathrm{CO}$ as a molecular probe, our IR study has exhibited that the addition of $\mathrm{Pt}$ has enhanced the Co distribution and inhibited the carbon deposition on $\mathrm{Co} / \mathrm{Al}_{2} \mathrm{O}_{3}$ [1]. All of these previous studies indicate that better dispersion of the supported metal would benefit the decreasing of carbon deposition.

Here we present our recent investigation of the effect of support particle size on the carbon deposition. Three different types of $\mathrm{Co} / \mathrm{Al}_{2} \mathrm{O}_{3}$ catalysts were prepared with the same Co loading (10\%), including Co supported on commercial $\mathrm{Al}_{2} \mathrm{O}_{3}$ (Cat 1), Co supported on sol-gel-processed $\mathrm{Al}_{2} \mathrm{O}_{3}$ (Cat 2) and sol-gel-made homogeneous Co-in- $\mathrm{Al}_{2} \mathrm{O}_{3}$ (Cat 3). Cat 3 was prepared by sol-gel processing in the following procedure: $10 \mathrm{mmol}$ of aluminum tri-sec-butoxide (ASB, ACTOS 97\%) was dissolved in $150 \mathrm{mmol}$ of isopropanol (Fisher Scientific 99.9\%), and then $5 \mathrm{mmol}$ acetylacetone (Merck 99.5+\%) was added as chelating agent by refluxing the solution under nitrogen atmosphere. The precursor solution was vigorously stirred at room temperature for $30 \mathrm{~min}$. Nickel nitrate dissolved in about $60 \mathrm{mmol}$ of deionzed water was added drop by drop under mild stirring. The sample gelated in a few minutes. The resulting transparent and green gel was aged for 5 days at room temperature and dried at $333 \mathrm{~K}$ for 5 days. Then it was calcined at $873 \mathrm{~K}$ for $5 \mathrm{~h}$. Cat 1 and Cat 2 were prepared by incipient wetness

(C) 2000 IUPAC, Pure and Applied Chemistry 72, 327-331 
impregnation. Cat 1 employed commercial g- $\mathrm{Al}_{2} \mathrm{O}_{3}$ (Merck) as its support. The g- $\mathrm{Al}_{2} \mathrm{O}_{3}$ support of Cat 2 was synthesized following the above sol-gel procedure (for Cat 3), but only $60 \mathrm{mmol}$ of deionzed water without cobal nitrate was added during the sol-gel processing. The samples were calcined at $873 \mathrm{~K}$ for $5 \mathrm{~h}$. The loading of nickel was $10 \mathrm{wt} \%$ for all three catalysts.

The high-resolution TEM images in Fig.1 show that the size of the cobalt particles supported on commercial g- $\mathrm{Al}_{2} \mathrm{O}_{3}$ (Cat 1 ) is in the range of $20-40 \mathrm{~nm}$ while that on sol-gel-processed $\mathrm{Co} / \mathrm{Al}_{2} \mathrm{O}_{3}$ (Cat 3) is rather small, $<6 \mathrm{~nm}$ only. By using XRD and FTIR (see Fig. 2), Co was identified as crystalline $\mathrm{Co}_{3} \mathrm{O}_{4}$ in the as-prepared Cat 1 sample, $\mathrm{CoAl}_{2} \mathrm{O}_{4}$ in Cat 2 and amorphous $\mathrm{Co} / \mathrm{Al}_{2} \mathrm{O}_{3}$ in Cat 3, also indicating the best dispersion in Cat 3. The strong doublet i.r. bands at 663 and $568 \mathrm{~cm}^{-1}$ in Fig. 2a are typical $\mathrm{Co}-\mathrm{O}$ vibration in the cubic spinel structured $\mathrm{Co}_{3} \mathrm{O}_{4}$ [7], while the doublet peaks at 676 and $568 \mathrm{~cm}^{-1}$ in Fig. $2 \mathrm{~b}$ are characteristic of $\mathrm{CoAl}_{2} \mathrm{O}_{4}$ [8], in a good agreement with XRD results (not shown).

The specific surface area measured by BET method decreases in the order of Cat $3>$ Cat $2>>$ Cat 1 . The catalysts, which were obtained from sol-gel processing, had very high surface area, $183.2 \mathrm{~m}^{2} \mathrm{~g}^{-1}$, while the surface area of the catalyst on traditional $\mathrm{Al}_{2} \mathrm{O}_{3}$ support (Cat 1) was only $90.9 \mathrm{~m}^{2} \mathrm{~g}^{-1}$, about half of the former.

The catalytic activity and stability were evaluated on a quartz microreactor (I.D. $4 \mathrm{~mm}$ ) packed with $100 \mathrm{mg}$ of catalysts (35-50 mesh size). The catalysts were reduced in a flow of $\mathrm{H}_{2}(30 \mathrm{ml} / \mathrm{min}$ ) at $873 \mathrm{~K}$ for $1 \mathrm{~h}$ before a premixed feedstock $\left(19.8 \% \mathrm{CH}_{4} / 17.5 \% \mathrm{CO}_{2} / \mathrm{Ar}\right)$ was introduced into the catalyst bed. The outlet gas composition was measured by gas chromatography. The amount of coke deposited on the reacted catalysts was measured in situ by mass spectrometry as previously described in detail [5]. The catalytic activity of the three samples (Cats 1,2, and 3) was approximately the same as each other. However, there was a large difference in their resistance to coke. Cat 3 showed good coke resistivity and could last for longer than $20 \mathrm{~h}$ of reaction. A little coke was observed on Cat 2, whereas a large amount of coke was deposited on Cat 1 . It plugged the reactor completely within $1 \mathrm{~h}$ of reaction. This may suggest that the nanoscaled structure of the support is beneficial for the inhibition of coke formation. It is reasonable that high surface area can enhance the dispersion of active components, like cobalt on the sol-gel $\mathrm{Al}_{2} \mathrm{O}_{3}$, and thus prevent the segregation of cobalt on the surfaces. This reduces the number of sufficiently large ensembles of $\mathrm{Co}$ atoms, which are responsible for coke deposition [9]. Therefore, the outstanding performance and excellent coking resistance of the sol-gel-processed $\mathrm{Co} / \mathrm{Al}_{2} \mathrm{O}_{3}$ catalyst for $\mathrm{CO}_{2}$ reforming of methane may be greatly related to its nanostructure of the support, high BET surface area, and high distribution of cobalt. Recently, we have found that a sol-gel-processed $\mathrm{Ni} / \mathrm{Al}_{2} \mathrm{O}_{3}$ catalyst prepared by the same procedure has an excellent coking resistivity during the methane $\mathrm{CO}_{2}$ reforming. It could last more than $80 \mathrm{~h}$ of reaction with little coke deposition, whereas the Ni catalyst supported on commercial $\mathrm{g}-\mathrm{Al}_{2} \mathrm{O}_{3}$ only lasted $3 \mathrm{~h}$, owing to complete shattering of catalyst. This further supports the above views.

In summary, the metal distribution in supported catalysts can be controlled by the crystalline structure of the support, the metal/support ratio, the alloying, and the preparation procedures of the support. By sol-gel processing, nanostructured Co can be made, showing excellent activity and stability for the methane $\mathrm{CO}_{2}$ reforming.

\section{REFERENCES}

1. S. Tang, J. Lin, K. L. Tan. Catal. Lett. 59, 129 (1999).

2. L. Guczi, R. A. Van Santen, K. V. Sarma. Catal. Rev._Sci. Eng. 38, 249 (1996).

3. T. V. Choudhary and D. W. Goodman. Catal. Lett 59, 93 (1999).

4. P. Chen, X. Wu, J. Lin, K. L. Tan. Science 91, 285 (1999). 
5. S. Tang, J. Lin, K. L. Tan. Catal. Lett. 51, 169 (1998).

6. X. Wu, P. Chen, J. Lin, K. L. Tan. J. Hydrg. Energ. in press (1999).

7. G. Busca, R. Guidetti, V. Lorenzelli. J. Chem. Soc. Faraday Trans. 86, 989 (1990).

8. G. Busca, V. Lorenzelli, V. Bolis. Mater. Chem. Phys. 31, 221 (1992).

9. J. R. Rostrup-Nielsen. J. Catal. 85, 31 (1984). 